\title{
Defensive Gun Use (DGU) in the American Gun Debate
}

\author{
Karol Mazur ${ }^{1}$, Justyna Hasij ${ }^{2}$ \\ ${ }^{1}$ MA in Political Science. PhD Candidate at The Institute of Political Studies, Polish Academy of Sciences \\ Poland \\ ${ }^{2}$ The Higher School of Strategic Planning in Dabrowa Gornicza \\ Kościelna 6, 41-300 Dąrowa Górnicza - Poland
}

\begin{abstract}
In this article, it is attempted to present a crosssectional view on the issue of defensive gun use (DGU) in the United States. This issue is a key element in the US gun control debate that is currently underway in the academic community; criminologists, economists, political scientists and researchers dealing with broadly understood public health. Research in this area and the data obtained are also one of the pillars arguments of the defenders of the United States' 2nd Amendment to the Constitution. The article uses a selective review of the conclusions of the leading researchers and representatives in this field.
\end{abstract}

Index Terms- DGU, (S)DGU, Defensive Gun Use, Right to Keep and Bear Arms, 2nd Amendment.

\section{DEFINING DGU AND THE SIGNIFICANCE OF THE NATIONAL CRIME VICTIMIZATION SURVEY STATISTICS}

The debate on gun rights has been going on in the United States for many decades, but without major decisions. Both, the supporters of the 2nd Amendment to the Constitution and its opponents are trying to demonstrate the significant impact of access to firearms on the so-called public order and security. The 2nd Amendment to the United States Constitution, adopted under the Bill of Rights, entered into force in 1791, guaranteeing citizens the right to keep and bear arms. It is worded as follows: "A well-regulated Militia, being necessary to the security of a Free State, the right of the people to keep and bear Arms, shall not be infringed."

Activists and researchers construct appropriate terms for gun control debate purpose, collecting statistical data that allows for a relatively precise look at the discussed problem. Defensive Gun Use or Self-Defensive Gun Use is one of such terms. The simplest definition of defensive gun use (DGU) is that lawabiding citizens with firearms effectively prevent, eliminate or simply deter potential aggressors and attackers before and during a robbery or an assault. These cases constitute, for proponents of access to guns, the basic argument for

ASEJ - Scientific Journal of Bielsko-Biala School of

Finance and Law

Volume 24, No 2 (2020), 6 pages

DOI: $10.5604 / 01.3001 .0014 .3280$

Received: 10.06.2020; Accepted: 24.06.2020 maintaining the current regulations, and even for their liberalization, where, after tightening them, there is a clear increase in crime. In the opinion of the supporters of the 2 nd Amendment, it is possible to look at the issue of access of firearms from a different perspective, which is often overlooked in the broadly understood public debate.

Therefore, statistics and data from DGU rely on the sum of event registrations that can be qualified to the so-called positive effect of having a gun. On the other hand, the positive effect of having a gun can be defined as a situation in which the gun allowed the victims to repel the attack satisfactorily only for themselves and the environment. In other words, the less damage to a potential but armed victim, the greater the justification for having a gun. DGU issues have been known for many decades, but in the United States it appeared in scientific journals, especially in criminological studies, only in the early 1990s. These studies were supposed to be a substantive and, what is more important, scientific answer to the statistics cited by opponents of universal access to guns, talking about the scale of violence with the use of firearms on the streets of cities. Previous conclusions from research on access to firearms, before the DGU concept appeared in the sphere of scientific interest, left no doubt and prompted researchers to accept the position that the more guns in society and households, the greater the risk of increased violence with the use of it. The dogma prevailing was that possession of a gun is dangerous not only for third parties, but also for the owners themselves. In addition to the escalation of violence with guns, accidental shootings and a high rate of suicide using firearms have dominated the discussion about access to guns. Indeed, in these years, the scale of violence related to firearms in the United States was a significant social problem (Sessions, 2017). This problem resulted in legislative attempts to resolve the whole issue quickly and radically. Regulations and meticulous restrictions in the availability of firearms turned out to be one obvious solution.

The fruit of these considerations were far-reaching changes

Regular research paper: Published 06.2020

Corresponding author's e-mail: mazur.karol@gmail.com

Copyright (C) 2018 This is an open access article distributed under the Creative Commons Attribution CC-BY-NC 4.0 License. 
in law implemented in the early 1990s. On November 30, 1993, at the initiative of the United States Congress, the so-called Brady's Act of checking the applicant's criminal past, this record consequently extends the entire procedure up to five days. It can also be said, after a clear review of American literature documenting the history of the struggles of state administration with firearms, that around the mid-1960s restrictions on its access have been gradually increasing (Poznaniak, 2003, pp. 268-269). The first major regulations and legal provisions began to access to guns. It should be noted that regulations were also gradually implemented in earlier years. Due to the scale of the problem, they were not so significant at the time in this dispute (Spitzer, 2017). In short, it was forbidden to allow selling guns to minors, the mentally ill and drug addicts. As the circles defending the fundamental constitutional principle resulting from the Second Amendment considered some of the above regulations to be unfavorable and violating civil rights, not only the debate on this matter started, but also some research began to emphasize the positive side of possessing guns. Another aim was to bring reflection on the progressive regulations based on the existing literature of firearms opponents. It is worth noting that about 140 years after the entry into force of the 2 nd Amendment, i.e. from 1791, the United States did not regulate the issue of access to guns until 1934, when one of the first regulations called the National Firearms Act was introduced.

The beginning of the general debate on DGU that has been continued to this day since 1995, was started by two researchers Gary Kleck and Marc Gertz. These researchers made their first serious attempt to define and depict how often Americans reach for guns in self-defense (Kleck and Gertz, 1995). The article, which was based mainly on their own survey, began the academic discussion on DGU issues which has been continued to this day. Conclusions from this debate seem to be far from a final compromise, and the research of each side of the dispute very often turns out to be quite different. Issues related to DGU (S-DGU) are based not only on scientists' own surveys. These researchers, which should be emphasized, use mainly the conclusions of the National Crime Victimization Survey (NCVS). NCVS is a unit administered by the Bureau of Justice Statistics, which conducts national surveys, depending on the subject matter and the task of analyzing the problem, in the range of tens to even several hundred thousand households in the United States. These statistics are not flawless but their quality cannot be questioned. These data seem to quite successfully supplement separate research of scientists in this area. NCVS surveys allow you to analyze the use of guns on a defensive basis each year. Unfortunately, the survey system requires scientists dealing with this issue to be extremely careful when formulating their final conclusions. As with any survey process, researchers must be aware of the fact that in this case there is a very large margin of error in the analysis of input data. Sampling is not always well prepared. The respondents are in the habit of either misrepresenting answers or, just as importantly, they are simply mistaken in assessing the situation in which they find themselves.

Unfortunately, based on the NCVS data, in most cases, as already mentioned, various statistical conclusions are drawn. Obtaining different results would not be so controversial, if not for the fact that legal solutions are finally formulated on their basis in individual states. These studies can obviously serve as an argument in forcing such or other regulations. However, before we move on to presenting selected and leading research literature in this area, it should be mentioned that the differences in the obtained results, unfortunately, do not present the picture of the DGU issue clearly. In other words, these studies are so disputable that it is not yet necessary to draw final conclusions on such a key issue as the right to own a gun conditioned by a constitutional provision. For the purposes of this article, we do not undertake an analysis of the very interpretation of the 2nd Amendment, which has been the subject of dispute for years in terms of US Supreme Court rulings. We have therefore adopted the current status and actual status as the indicator.

Therefore, these studies should be successively continued until appropriate expert consensus is obtained when suggesting specific legal solutions in the face of previously obtained unambiguous conclusions. The structure of the survey is not particularly complicated, it takes into account classic situational factors (Hart and Miethe, 2009, pp. 10-11). Therefore, respondents are sorted according to specific event patterns.

TABLE 1. AN EXAMPLE DIAGRAM OF THE SITUATIONAL FACTOR

\begin{tabular}{|l|l|}
\hline Type of crime & $\begin{array}{l}\text { Rape / Sexual Assault / Robbery / Physical } \\
\text { Attack }\end{array}$ \\
\hline Armed criminal & Yes / No \\
\hline Place of incident & Public Place / House / Home \\
\hline Time of incident & Day / Night \\
\hline $\begin{array}{l}\text { A criminal under } \\
\text { the influence of } \\
\text { drugs / alcohol }\end{array}$ & \begin{tabular}{l} 
Yes / No / Can't Tell (No testing or no \\
\hline
\end{tabular} \\
\hline
\end{tabular}

Source: Own study based on T.C. Hart, T. D. Miethe (2000), Self-Defensive Gun Use by Crime Victims. A Conjunctive Analysis of Its Situational Contexts, Journal of Contemporary Criminal Justice Vol. $25 \mathrm{nr} 1$.

\section{BASIC CONCLUSIONS FROM DGU RESEARCHERS' REPORTS}

The appearance of the DGU survey system dates back to the 1970 s, when the first, coherent research methods were constructed. The first advanced works in this area were also appeared (Cook and Goss, 2014, p. 18). Respondents for NCVS indicated an average of 1 in 100 defensive use cases. These data meant that annually changes could be observed in this area. In their pioneering and ground-breaking article from 1995, Gary Kleck and Marc Gertz showed that Americans very often reach for guns in self-defensive. Based on surveys and prepared questionnaires, they showed, with impressive results, 2.5 million cases of defensive gun use per year (Kleck and Gertz, 1995). The average values were indeed impressive, because the conclusions of Kleck and Gertz suggested that this gives more than 6,800 cases per day. However, the picture of the NCVS survey results was different, which indicated that only 70,000 cases of this type occurred (Cook and Goss, 2014, p. 19). 
Therefore, the key question arose why there were such drastic differences in the results? An important reason is, of course, the fact that NCVS surveyed only those people whose cases were registered, e.g. with the police. Therefore, there was certainty that the respondents were indeed victims of violence and their qualification for statistics is appropriate and reasonable. Kleck and Gertz unfortunately did not do this in their article, and simply extrapolated their results to the entire population, i.e. also to those who were not subject to such registration or who did not report to inform the relevant authorities about being attacked. A significant problem therefore arises. NCVS surveys may suggest DGU underestimation because they do not include this parameter. On the other hand, Kleck's and Gertz' research could overestimate the positive aspect of the gun because presumably the surveyed people could lie or not fully understand the nature and essence of the study itself. The design of the Kleck and Gertz survey omitted the question of verifying whether the respondent was in a real situation subject to being included in DGU statistics. Kleck and Gertz, however, did not focus only on the sum of DGU cases. They split the data into individual, important components of the whole issue. It allowed looking at DGU issues from the expected number of specific events.

CHART. 1. \% OF CASES AND THE ESTIMATED NUMBER OF DGU SITUATIONS

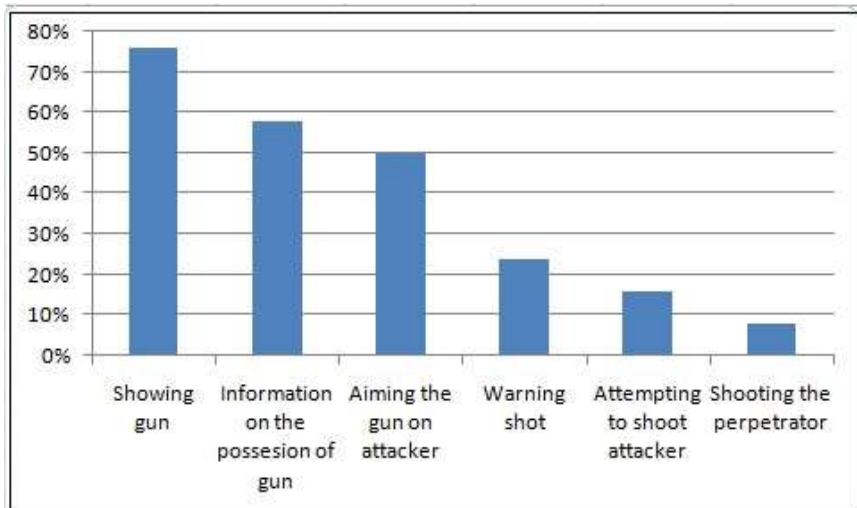

Source: Based on G. Kleck, M. Gertz (1996), Armed Resistance to Crime: The Prevalence and Nature of Self-Defense with a Gun, Journal of Criminal Law and Criminology, Vol. 86 Issue 1, Art. 8, p.185.

Therefore, if the above data is considered valuable and relatively appropriate, then the observation arises that cases where the perpetrator / assailant is killed by his victim may occur on the scale of general potential DGU events extremely rarely. According to Kleck and Gertz, the DGU's biggest advantage is the very deterrence of potential aggressors and criminals. According to these researchers, only in $8 \%$ of cases when guns are used in self-defense, it may end up shooting the attacker. This means, on average, about one case in a thousand of cases. I must admit that the picture resulting from the above research is highly optimistic for proponents of the right to own a gun. There are, however, many inaccuracies and questions about surveying that are worth examining again. There is a certain margin of error for the NCVS survey.

The next important question arises, who is more wrong in these analyzes? Errors in the survey results presented by NCVS seem to be smaller, at least due to the compliance with standard procedures, there is a smaller the probability of a large scale of error. It is quite the opposite of inference from the results of the above-mentioned researchers. Although, of course, this issue is certainly highly debatable, adopting the ad hoc assumption here as to the priority in the reliability of the government's diminishing report. In fact, in Kleck and Gertz's research may, although of course not have to be unreasonable and constitute gross dishonesty or inconsistency from the point of view of science. In such an important matter, therefore, it is necessary to adopt and analyze all the criteria that are available to us, because the more research in this area by different researchers, the more accurate picture of the issue can be obviously clarified. An important element of the analysis is also the caesura and time frame of the event, i.e. when it happened, how long ago it occurred in comparison with the current survey. In this type of research, it should be remembered that in the survey statistics, the so-called telescopic effect can completely distort the final result.

The key question is how DGU is perceived by the average citizen surveyed himself? In other words, illustrating a specific example, as suggested by researchers Philip J. Cook and Kristin A. Goss: someone who got into a random fight in a roadside pub, pulled out a revolver and scared his opponent, is he entitled to be included in the research on DGU? (Cook and Goss 2014, p. 19). The perception of the criterion of defensive gun use seems to be different in the minds of citizens. The case is important because if Kleck and Gertz's conclusions were correct, this would put the right to own firearms in a different light, as it would justify the costs incurred in relation to the benefits. Supporters of the Second Amendment would therefore have a solid argument in hand to support their thesis about the positive effect of having firearms among citizens. However, NCVS surveys show that exaggerated optimism in this matter is not advisable and it is not possible to narrow down or summarize the issues to just one study.

Therefore, in the academic circle there was strong opposition to the conclusions of the 1995 article. One of the loudest adversaries of Kleck and Gertz turned out to be David Hemenway, a scientist from Harvard University, dealing with Health Policy and management in Public Health. Hemenway, as a staunch opponent of easy access to guns, in his response suggested that DGU is definitely overstated and he pointed to the methodological errors of the authors (Hemenway, 2017). He questioned Kleck and Gertz in one of his articles stating that surveys about rare events can and usually lead to glaring overestimations, and the methodology, the construction of questions and the questionnaire seem to be, if not incorrect, very simplified in relation to the issues they claim to solve. Based on such poor design and overestimation, no reliable conclusions can be drawn about the DGU in the United States (Hemenway,1997, pp.1443-1444). Hemenway confirmed his position in subsequent articles and applications received. In 2015, together with a researcher from the University of Vermont, Sara J. Solnick, he conducted a study in which he found that out of 14,000 respondents who were victims of violence, only 127 cases (i.e. $0.9 \%$ ) were eligible to be included in the DGU or (S)DGU (Hemenway and Solnick, 2015, p. 22). 
From the remaining conclusions, the researchers pointed out that DGU is much more common among men living in rural areas and the cases themselves in an overwhelming number take place outside the home of the victims of violence. Interesting information also resulting from the above research by Hemenway and Solnick is to show that despite having guns for self-defense purposes, it reduces the perception of the level of security among other members of the community. Hemenway claims that his many years of research show that the number of cases of defensive gun use seems to be much lower. Hemenway gained confidence about the overestimation in the research of his opponents mainly thanks to the already occurring in equestionnaires errors. Cautious estimates finally allow to conclude, according to Hemenway, that this indicator oscillates around a maximum of 80 thousand cases per year (Baum, 2018, p. 373).

Further in the DGU discussion, Hemenway reverses the dependence of gun use. He concludes that criminals very often admit that they are forced to use more violent actions because their victims are armed (Hemenway 2017, pp. 77-78). In other words, Hemenway admits that criminals can be more violent if they know that their victims can resist using firearms. The criminal, according to Henenway, in many cases follows the principle of "you do not have to kill the victim if he does not resist". Therefore, it suggests that passive resistance statistically may pay off more. There is indeed a high probability that criminals will be more violent

and firm or that they will simply change their tactics in a costing situation. Apart from other aspects related to the possession of guns, of course, the profits and costs of using guns are difficult to assess so clearly (Cook and Ludwig, 1997, p. 10).

Therefore, reversal of dependence forces the researcher from Harvard to conclude that the only reasonable solution is prudent and a more restrictive policy of access to guns. Only in this way, according to Hemenway, one can minimize the losses and costs that result from owning a firearm. In his claims of high effectiveness and high saturation of DGU cases among American citizens who are victims of violence, Kleck and Gertz, however, are not alone. Some researchers support their conclusions, and express similar views.

Lawrence Southwick from the University of Buffalo analyzes the DGU problem including behavioral modeling, how the parties confront themselves and how the victims of the attack react. Using the NCVS data, Southwick states that in confrontation with criminals for law-abiding citizens, however, the most effective form of defense is having a firearm, e.g. a pistol (Southwick Jr. 2000, pp. 351-370). He notes that every citizen who confronts a criminal or assailant suffers losses and costs that are relatively simple to estimate. Nevertheless, these losses are lower if the victim has a firearm than when the victim does not. Importantly, Southwick also states that in addition to the fact that the victim armed with firearms is less injured in the confrontation, he also thinks that the criminals themselves seem to take into account the fact, whether their victim is surely armed. The attacker, according to the researcher, calculates the situation of his victim.
This classic reasoning in defense of the right to own a gun also allows one to understand why, the supporters of this right firmly defend this assumption that the gun simply equalizes the chances of the victim in a conflict situation with an armed attacker (Gorman and Kopel, 2005, pp. 92-100). Uncompromising defense of this thesis then forces us to adopt the position that access to a gun should not be particularly difficult for a law-abiding citizen, and the criteria for obtaining a permit are relatively simple to meet. Before we come to the conclusions in the DGU research, it is worth mentioning one more important research. These studies are undoubtedly one of the most extreme forms of defense of DGU, but they are worth presenting here. These are the studies of John R. Lott, an economist, a representative of the methodology of the "Chicago school of Economics". Lott's research series finally resulted in a substantial and controversial publication of his authorship. Lott made an extremely bold and iconoclastic thesis in researching the right to own a gun; he simply stated that the more guns, the less crimes (Lott, 2010).

Lott's publication caused quite a stir, and the economist himself became by far the most radical advocate of the 2 nd Amendment in the entire academic community. Many years after the publication of the first edition of the book, Lott's studies, despite his quite a few surprising mishaps, are still cited by supporters of the 2 nd Amendment. Lott is also cited despite of the fact that a large number of publications have appeared which question the absurdity of the "Chicago" economist. Regardless of the controversial conclusions drawn from John $\mathrm{R}$. Lott's research, it is worth mentioning that this economist, as one of the few participants in the dispute, drew attention to two fundamental issues, extremely important to supplement the discussed debate. In the first case, Lott stated that the public debate on the right to own guns in the United States is conducted in a one-way manner, and hence is far from an objective, emotionless, expert approach. In support of his position, he pointed out that government reports that inform the public about annual killings using firearms do not provide an analogous situation when the gun is used to save lives. This is especially the case for government reports that would take into account the DGU problem we are discussing (Lott, 2003).

In the second extremely important case, Lott, along with another economist, Stephen G. Bronars, showed that there are very strong indications that criminals are migrating from regions where firearms regulations are relatively liberal for citizens, to areas where stricter rules exist in this respect (Bronars and Lott, 1998). In conclusion, Lott and Bronars noted in their article an interesting relationship: criminals tend to move, responding to changes in regulations on the so-called concealed carrying of guns (called Concealed Carry). This factor has a far greater impact on migration than the arrest rate. Regarding finding a consensus on the above-mentioned research, in 2005 the first serious attempt to resolve the dispute arising from the divergent conclusions of Gary Kleck and David Hemenway appeared. The National Research Council (NRC) published a publication analyzing the conclusions of the abovementioned researchers. The Council has shown that no causal link can be established between the right to own a gun and the 
crime rate (Wellford, Pepper and Petrie, 2005).

Data difficult to estimate and interpret, too many factors and variables, force researchers trying to draw the right and correct DGU question in the light of scientific research, conclusions for further expertise in this field. Disputes between scientists are, fortunately, the reason for this kind of research. The unanimity of the conclusions means that research teams do not abandon the subject of the right to own a gun and its impact on crime levels and public health. As part of the summary of the DGU study, however, it seems that apart from the obvious numerical estimates, the key issue for the whole matter is missing in the whole debate. It is recalled by Dan Baum, a writer and New York columnist. Baum, surprised, states that he has gone through all arguments and the most obvious was that both sides had lost sight of something obvious: even the lower Hemenway number was huge anyway. Just eighty thousand cases a year meant that two hundred and twenty times a day Americans in one way or another used firearms for self-defense. So eight times more Americans saved themselves with a gun than died from it (Baum, 2018, p. 49). So Baum suggests that, regardless of the results of previous studies, these numbers are impressive in each of these studies, without exception. Even among those researchers who sought to negate or simply discredit Keck's and Gertz's ground-breaking article from 1995.

Such a look at the DGU issue also forces a final reflection on the fact that if we accepted even the least favorable numerical research results for DGU supporters, namely those with the lowest rate of defensive gun use, then as a result we would have very strong reasons to believe that a large group of Americans simply do not report to the police the events in which they participated. It would be typed in broadly understood "gun culture", one of which is the essence of self-defense. Also, correction of errors resulting from surveys would not negate the impressive number of DGU cases per year. This is a very strong message and reliable argument over the analysis of the issue of defensive use of firearms in the United States. A cursory calculation of profits and losses allows us to tip the balance in favor of the defenders of the current 2 nd Amendment. So that we are only arguing about details in numbers, and the issue itself undoubtedly has a positive balance? To answer this question, of course, the DGU research perspective should be considered open. This point of view should be taken contrary to what the proponents of the right to own guns claim, who, referring to statistics that are favorable to their perspective, suggest, as a result, that the debate on the availability of guns is already over (Wilson, 2015).

\section{RESEARCH PERSPECTIVE ON DGU}

Statistics on fatalities due to the use of firearms in the United States seem to suggest that decisive solutions should be introduced. Regulations and legislative proposals can ultimately help minimize the scale of violence with firearms. In favor of regulations, hard and public murder data predominate. In the United States, from 1999 to 2012 there was a fairly glaring increase in deaths caused by the use of firearms. In these years, the number of deaths increased by 3,289. More specifically, in 1999 it was 28,874 victims, while in 2012 the number increased to 32,163 victims (Soboń, 2017, p. 170). However, the information is alarming that among these data, as many as 15,953 fatalities, or almost half of them, are the result of murder. Some researchers additionally suggest that we are dealing with a worrying increase in the so-called Mass Shooting and mass murders (Bjelopera et al., 2013). Unfortunately, the analysis of these seemingly obvious data does not allow us to draw unambiguous conclusions. And although the leading activists of such pro-shooting organizations like the National Rifle Association (NRA) try to keep the discussion under the guise of a scientific framework, their numerical combinations often distort the essence and seriousness of the whole issue. Underestimating the phenomena of violence, in the face of unfavorable statistical conclusions, is often summarized to the level of absurd rhetoric. Analogies in the debate, e.g. the comparison of fatalities of firearms with road fatalities constitute an attempt to relativize this data.

NRA spokesmen see, therefore, either the bad will of their opponents, the drawing of unjustified correlations, or simply unfair legislative proposals resulting from openly hostile political environments. Meanwhile, in our view, the prospect of research into the right to own a gun in the United States is definitely not complete, regardless of its political implications. This should be considered, despite the currently favorable supporters' right to own a gun, by the jurisprudence of the Supreme Court. Research cannot be completed when so many different positions seem to be presented based on the same available data and statistics.

At present, however, it is worth realizing that it is the political rivalry between individual camps and party factions that sets the course further towards potential legal solutions. The social debate in itself does not bring any significant solutions or legal proposals for the problem. The political race drives this discussion to such an extent that as the years go by, the American society becomes increasingly polarized in this matter (Goldberg, 2017). It is time, however, for Gun Culture to face the challenges of public order and security. In other words, the 2nd Amendment must meet the demands of time, which brings not only technological changes but also those concerning the functioning of societies themselves. Guns nowadays are definitely more lethal, easier to use and have a much greater firepower than earlier pieces or counterparts. In our opinion, the personal involvement of political elites in the United States in the debate on the scope of the right to own guns has also not yet resolved this sensitive issue. Therefore, research on DGU will and must be successively carried out and continued, and academic circles should definitely increase their expenditure in this area. Possible regulations or even radical regulation in access to firearms, however, must take into account civic aspects when creating the law. In other words, the evolution of regulations must proceed in an extremely gradual and restrained manner, so as not to violate the law-abiding rights and observing the rules of social coexistence of people. Enforcing restrictive regulations may be difficult to accept by people for whom guns in the United States are an attribute of freedom, patriotism or security (Harsanyi, 2018). 
It is extremely important and useful, therefore, that DGU is one of those elements of the debate on the 2nd Amendment, which allows to look at this problem from the purely practical functioning and use of guns in society, and therefore its importance remains invaluable. If science and its research method of measurement are able to show clearly defined relationships, they should be considered as a priority in the entire debate on potential law correction. This must be done in a far more robust way than when the premises for the right to own a firearm or its confiscation arise from purely ideological reasons. In our opinion, the coming years in the United States will be dominated by the problem related to access to firearms, and the issue of DGU will play an important role here. An open question, which cannot be satisfactorily answered in the current state of knowledge, is, of course, what direction the law will ultimately take. The coming years will surely give us such an answer, so they will be extremely developmental and promising, for both sides for this type of research and for the researchers themselves dealing with this topic.

\section{REFERENCES}

Baum D. (2018), Wolność i spluwa. Podróż przez uzbrojona Amerykę, Wydawnictwo Czarne, Warszawa.

Bjelopera, J. P. ed.(2013), Public Mass Shootings in the United States: Selected Implications for Federal Public Health and Safety Policy, https://fas.org/sgp/crs/misc/R43004.pdf (accessed 18.06.2020).

Bronars S.G., Lott J.R. (1998), Criminal Deterrence, Geographic Spillovers, and Right-to-Carry Concealed Handguns, American Economic Review, Vol. 88 , nr 2, May.

Cook P.J., Goss K.A. (2014), The Gun Debate. What Everybody Needs to Know, Oxford University Press, New York.

Cook P.J., Ludwig J. (1997), Guns in America: National Survey on Private Ownership and Use Firearms, National Institute of Justice, Research in Brief, May, p. 10.

Goldberg J. (2017), Why America is Divided in Guns? https://www.aei.org/articles/why-america-is-divided-on-guns/ (accessed 18.06.2020).

Gorman L., Kopel D.B. (2005), Self-Defense: The Equalizer, Applied Research and Public Policy June, pp. 92-100.

Harsanyi D. (2018), First Freedom. A Ride Through America's Enduring History with the Gun, Threshold Editions, New York.

Hart T.C., Miethe T.D. (2009), Self-Defensive Gun Use by Crime Victims. A Conjunctive Analysis of Its Situational Contexts, Journal of Contemporary Criminal Justice Vol. 25 [1], pp. 10-11.

Hemenway D. (2017), Private Guns, Public Health, University of Michigan.

Hemenway D. (1997), Survey Research and Self-Defense Gun Use: An Explanation of Extreme Overestimates, Journal of Criminal Law and Criminology, Vol. 87 Is. 4, pp. 1443-1444.

Hemenway D., Solnick S.J. (2015), The Epidemiology of Self-Defense Gun Use: Evidence from the National Crime Victimization Surveys 2007-2011, Preventive Medicine, Vol. 79, November, p. 22.

Kleck G., Gertz M. (1995), Armed Resistance to Crime: The Prevalence and Nature of Self-Defense with a Gun, Journal of Criminal Law and Criminology, Vol. 86 Issue 1, Art. 8.

Lott J.R. (2010), More Guns, Less Crime. Understanding Crime and Gun Control Laws, University of Chicago Press, Chicago.
Lott J.R. (2003), The Bias Against Guns. Why Almost Everything You've Heard About Gun Control is Wrong, Regnery Publishing, Inc., Washington DC.

Poznaniak W. (2003), Spoleczno-psychologiczne aspekty posiadania broni, Ruch Prawniczy i Ekonomiczny, Zeszyt 2, pp. 268-269.

Sessions J. (2017), Violent Crime Some Still Well Historical Highs, https://www.politifact.com/truth-o-meter/statements/2017/dec/04/jeff-

sessions/violent-crime-some-still-well-historical-highs/ (accessed 18.06.2020).

Soboń M. (2017), Międzynarodowy obrót bronią konwencjonalna, Fundacja $\mathrm{Na}$ Rzecz Czystej Energii, Poznań.

Southwick Jr. L. (2000), Self-defense with guns The consequences, Journal of Criminal Justice Vol. 28, pp. 351-370.

Spitzer J. (2017), Gun Law History in The United States and Second Amendment Rights, Law and Contemporary Problems Vol. 80:55 No. 2.

Wellford Ch.F., Pepper J.V., Petrie C.V. (2005), Firearms and Violence: A Critical Review, National Research Council of The National Academies, https://www.nap.edu/catalog/10881/firearms-and-violence-a-critical-review (accessed 18.06.2020)

Wilson H.L. (2015), The Triumph of the Gun Rights Argument. Why the Gun Control Debate Is Over?ABC CLIO, CA. 